This is a postprint version of the following published document:

Pérez-Prior, T.; Várez, A.; Levenfeld, B. Synthesis and characterization of benzimidazolium-functionalized polysulfones as anion-exchange membranes, In: Journal of Polymer Science, Part A: Polymer Chemistry, 53(20), October 2015, Pp. 2363-2373

DOI: https://doi.org/10.1002/pola.27692

(C) 2015 Wiley Periodicals, Inc. 


\title{
Synthesis and Characterization of Benzimidazolium-Functionalized Polysulfones as Anion-Exchange Membranes
}

\author{
María Teresa Pérez-Prior, Alejandro Várez, Belén Levenfeld \\ Department of Materials Science and Engineering and Chemical Engineering, Universidad Carlos III de Madrid, Avda. \\ Universidad, 30, E-28911- Leganés, Spain \\ Correspondence to: M.T. Pérez-Prior (E-mail: maperezp@ing.uc3m.es)
}

Received 2 March 2015; accepted 4 May 2015; published online 00 Month 2015

DOI: $10.1002 /$ pola.27692

ABSTRACT: Anion-exchange membranes containing pendant benzimidazolium groups were synthesized from polysulfone by chrolomethylation followed by nucleophilic substitution reaction with 1-methylbenzimidazole. The structures of the polymers were characterized by ${ }^{1} \mathrm{H}-\mathrm{NMR}$ and FTIR analysis. The resulting membranes showed high thermal stability below $200{ }^{\circ} \mathrm{C}$. The values of water uptake and swelling degree increased with the ion-exchange capacity of the polymeric membrane. The ionic conductivity was measured by means of impedance spectroscopy in aqueous solution of potassium hydroxide $\left(10^{-4}-10^{-1}\right.$ $M)$. The results show not only a clear correlation between the membrane's electrochemical behaviour with the electrolyte solution embedded in the membrane, but also with the degree of the polysulfone's chloromethylation.Thus, the ionic conductivity increased more than two orders of magnitude when the degree of chloromethylation increased from 40 to $140 \%$. Benzimidazolium-functionalized polysulfones exhibited better thermal, mechanical, and electrochemical properties than the widely used polymeric membranes containing quaternary ammonium groups. (c) 2015 Wiley Periodicals, Inc. J. Polym. Sci., Part A: Polym. Chem. 2015, 00, 000-000

KEYWORDS: polysulfone; benzimidazolium; anion-exchange membrane; impedance spectroscopy; alkaline stability
INTRODUCTION In the last years, anion-exchange membrane fuel cells (AEMFCs) are gaining attention as environmental sustainable energy generation technology primarily because of they aim to overcome the drawbacks showing proton-exchange membrane fuel cells (PEMFCs). ${ }^{1}$ The high durability, ${ }^{2}$ the enhancement of the reaction kinetics for both oxygen reduction and fuel oxidation, ${ }^{3}$ or the potential to use nonprecious metal-based electrocatalysts such as silver, ${ }^{4}$ or nickel ${ }^{5,6}$ instead of platinum ones, are some of the most significant advantages of these kinds of fuel cells versus traditional PEMFCs.

In an AEMFC the anion-exchange membrane (AEM) is a key element as it is responsible for the transport of hydroxide ions in the cell. Hence, the performance of the fuel cell is strongly conditioned by the behavior of the AEM. So much so that, significant efforts have been carried out to develop new polymeric materials able to enhance the efficiency of the membrane., ${ }^{7,8}$ For instance, poly(2,6-dimethyl-1,4-phenylene oxide) (PPO), ${ }^{9}$ polybenzimidazole $(\mathrm{PBI}),{ }^{10}$ poly(arylene ether sulfone) (PES), ${ }^{11}$ poly(phthalazinone ether ketone) (PPEK), ${ }^{12}$ poly(vinyl alcohol) (PVA), ${ }^{13}$ or polysulfone $(\mathrm{PSU})^{14}$ are some of the most widely used polymers in the synthesis of AEMs.

Nevertheless, the efficiency of the membrane depends not only on the nature of the polymer backbone but also the anion exchangeable functional groups capable of transporting the hydroxide ions through the membrane. ${ }^{8}$ Quaternary ammonium groups (QA) have been extensively used for this purpose. ${ }^{8,15,16}$ However, these cations have the disadvantage of being rather unstable in alkaline solutions, due to the strong nucleophilicity of the $\mathrm{OH}^{-}$anions which induces $\mathrm{S}_{\mathrm{N}} 2$ displacement or Hofmann elimination when hydrogens in $\beta$ position are present. ${ }^{7}$ Nevertheless, they show better alkaline stability and fuel cell performance than the diammonium and quaternary phosphonium groups (QP). ${ }^{17}$ Alternative cationic groups like guanidinium ones have also used in $\mathrm{PPO}^{9}$ and $\mathrm{PES}^{18}$ membranes showing remarkably high ionic conductivity. Likewise, pyridinium based AEMs were prepared for alkaline fuel cells ${ }^{19}$ in spite of its low alkaline stability. Unlike these groups, imidazolium (Im) was proposed as a good alternative. The degradation of Im groups in alkaline environments could be minimized because of the existence of the $\pi$-conjugated structure of the five-member heterocyclic ring and the steric hindrance. ${ }^{20}$ Imidazolium-based ionic liquids have been applied for the preparation of $\mathrm{AEMs}^{21,22}$ due to their high ionic conductivity and excellent ionexchange capability. Yan et al. $^{23}$ synthesized a series of imidazolium-functionalized polysulfones (PSU-Im-OH) which showed high hydroxide conductivity and excellent thermal stability. In addition, imidazolium functionalized membranes 
based on $\mathrm{PPO}^{24}$ displayed enhanced short-term thermal and chemical stabilities compared with QA-type membranes.

In this study, a series of novel benzimidazoliumfunctionalized polysulfones (PSU-BIm-OH) were prepared. Benzimidazolium (BIm) shows a chemical structure similar to that of Im consisting on an imidazolium ring fused to benzene. Benzimidazole is part of PBI, a polymer known to exhibit high thermal and chemical stability as well as satisfactory mechanical properties. ${ }^{7}$ In fact, PBI has been widely used in both $\mathrm{PEMs}^{25}$ and AEMs. ${ }^{26}$ It is important to note that BIm groups can also be attached to the polymer chain and act as cationic groups in AEMs, thereby favoring the mobility and consequently the membrane ionic conductivity with respect to PBI. However, up to now, few research papers focused on the study of BIm as pendant ion exchange group have been reported. Recently, Lin et al. ${ }^{27}$ prepared BIm-functionalized membranes based on PPO. However, as far as we know, no reports on the development of BImfunctionalized AEM based on PSU have been published. PSU has been extensively used in AEMs synthesis ${ }^{5,28}$ due to its high thermal stability, good chemical resistance, and excellent mechanical properties. Both the PSU and PPO are thermoplastic engineering polymers which therefore share many properties. However, it is noteworthy to point out their different chemical structure. The most distinctive feature in the PSU is the presence of thediphenylene sulfone group which confersthe polymer molecule characteristics such as thermal stability, oxidative resistance and rigidness at high temperatures. ${ }^{29}$ When compared to PPO, PSU shows higher values for tensile strength at break and thermal conductivity. ${ }^{30}$ Thus, this work shows the synthesis and characterization of PSU-BIm-OH membranes by means of ${ }^{1} \mathrm{H}-\mathrm{NMR}$ and FTIR analysis. The properties of thermal stability, water uptake, swelling degree, mechanical behavior, ionic conductivity, and alkaline stability were also investigated and compared with those observed for the widely studied ammoniumfunctionalized polysulfones.

\section{EXPERIMENTAL}

\section{Materials and Reagents}

Polysulfone, tin (IV) chloride (99\%), paraformaldehyde (95.0-100.5\%), chlorotrimethylsilane ( $\geq 98 \%$ ), 1-methyl-2pyrrolidone (NMP) (ACS reagent, $\geq 99 \%$ ), 1-methyl benzimidazole (mBIm) (99\%), dimethylformamide- $\mathrm{d}_{7}$ (DMF$\left.d_{7}\right)(99.5 \% D)$, and dimethyl sulfoxide- $d_{6}\left(\right.$ DMSO- $\left._{6}\right)(99.9 \%$ D) were purchased from Sigma-Aldrich. All the other reagents were of analytical grade.

\section{Chloromethylation of PSU}

The chloromethylation reaction of PSU was performed by using a mixture of paraformaldehyde/chlorotrimethylsilane as chloromethylating agent, tin (IV) chloride as catalyst, and chloroform as solvent ${ }^{31}$ avoiding thus the use of chloromethyl methyl ether that is considered carcinogenic. PSU ( $5 \mathrm{~g}$ ) was dissolved in chloroform $(250 \mathrm{~mL})$ with mechanical stirring in a three-neck round bottom flask and, after adding

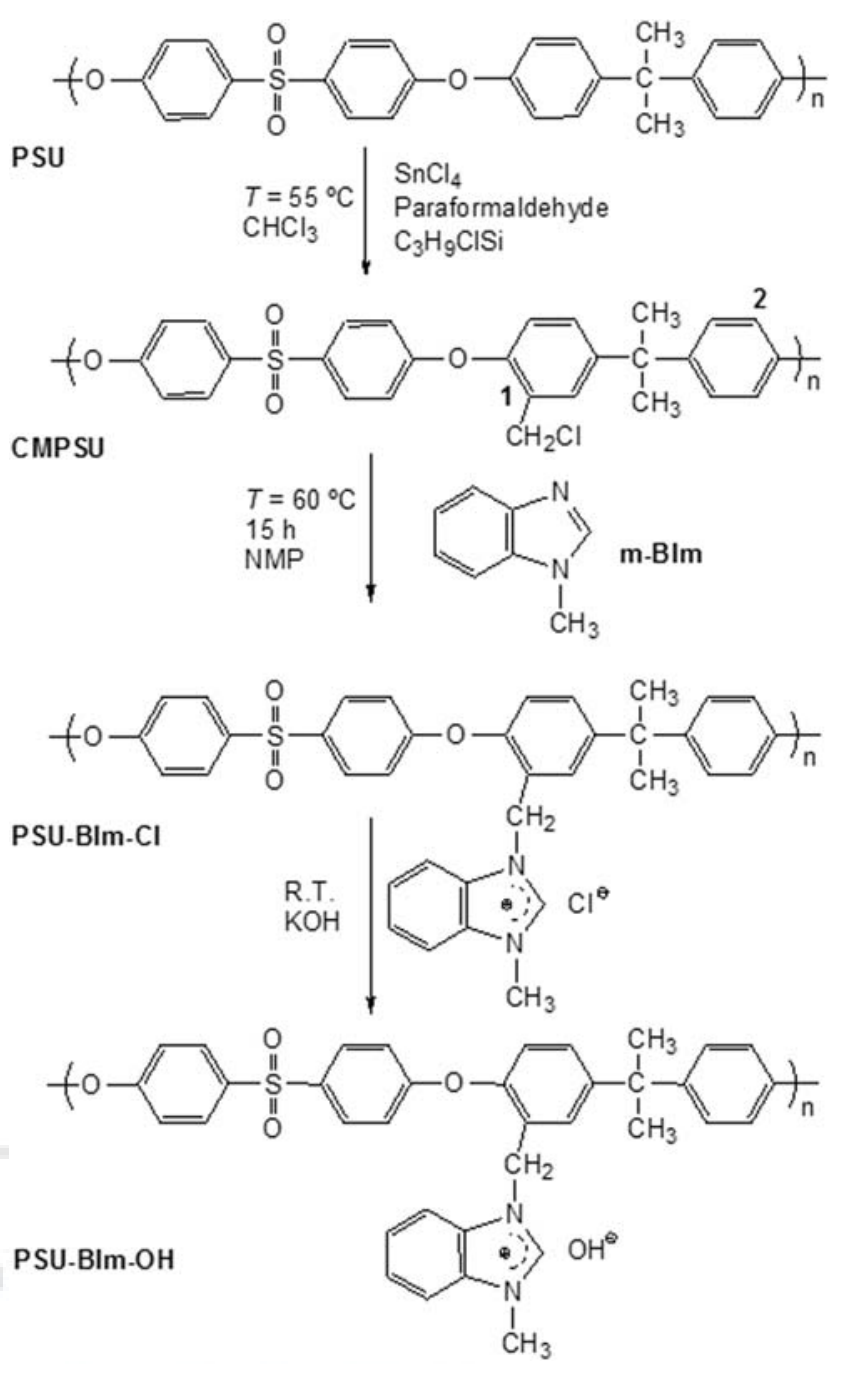

FIGURE 1 Scheme of the synthesis of PSU-BIm-OH.

stannic chloride $(0.27 \mathrm{~mL})$ and paraformaldehyde $(6.79 \mathrm{~g})$ to the solution, chlorotrimethylsilane $(28.64 \mathrm{~mL})$ was added dropwise. This solution was stirred at $55{ }^{\circ} \mathrm{C}$ for a certain time which varied from 24 to $72 \mathrm{~h}$ in order to obtain different degrees of chloromethylation (DC) of polysulfone. As shown in Figure 1 substitution takes place on the bisphenolA units, first in the position 1 leading to monosubstituted product and then in the position 2 when disubstituted product is obtained. ${ }^{32}$ The chloromethylated polysulfone (CMPSU) obtained was precipitated into ethanol, washed with deionized water, and dried at room temperature.

\section{Synthesis of PSU-BIm-OH Membrane}

The benzimidazolium chloride-functionalized polysulfone membrane (PSU-BIm-Cl) was synthesized via the nucleophilic substitution reaction of CMPSU with m-BIm as shown in Figure 1. Dried CMPSU (1.9 g) was dissolved in NMP (30 $\mathrm{mL}$ ) in a three-neck round bottom flask until complete dissolution. and next m-BIm (1.3 g) was added. The reaction mixture was maintained at $60{ }^{\circ} \mathrm{C}$ for $15 \mathrm{~h}$. The resulting solution containing PSU-BIm-Cl was cast onto a flat glass 
plate and dried in an oven by using a temperature program containing several steps from 30 to $100{ }^{\circ} \mathrm{C}$. PSU-BIm-OH membrane was prepared from the membrane in the $\mathrm{Cl}^{-}$ form. PSU-BIm-Cl membrane was immersed in a $1 \mathrm{M} \mathrm{KOH}$ solution for $48 \mathrm{~h}$ to replace $\mathrm{Cl}^{-}$with $\mathrm{OH}^{-}$. Finally, the membrane was repeatedly rinsed with deionized water until the $\mathrm{pH}$ of the residual water was neutral.

In this work, a series of benzimidazolium-functionalized polysulfones with different DC values of original polysulfone $(40,80,100$, and $140 \%)$ were prepared. The membranes were denoted as PSU-BIm-OH X\%, where $\mathrm{X} \%$ indicates the DC value.

\section{Measurements}

${ }^{1} \mathrm{H}-\mathrm{NMR}(300 \mathrm{MHz}$ ) analysis was performed on a Bruker Avance DPX-300 spectrometer using DMSO- $\mathrm{d}_{6}$ as solvent, except for PSU for which DMF- $\mathrm{d}_{7}$ was used due to its low solubility in DMSO- $\mathrm{d}_{6}$. TMS was used as the internal reference.

The FTIR spectra were recorded in a Perkin-Elmer Spectrum GX Instrument. The measurements were performed directly on the membrane in the $4000-400 \mathrm{~cm}^{-1}$ range and 16 scans were taken at a resolution of $4 \mathrm{~cm}^{-1}$.

\section{Scanning Electron Microscopy}

The morphology of the benzimidazolium-functionalized membranes was studied by Scanning Electron Microscopy (SEM). A Philips XL-30 scanning electron microscope operating at $15 \mathrm{kV}$ was used. To view the cross-section of the membranes, all samples were fractured after soaking in cryogenic conditions. Before inspection, samples were dried and coated with gold.

\section{Gel Permeation Chromatography}

Gel permeation chromatography (GPC) analysis was carried out in a Perkin Elmer chromatography system with Styragel $(300 \times 7.8 \mathrm{~mm}, 5 \mu \mathrm{m}$ particle size $)$ Polymer Laboratories columns. DMF with $0.1 \% \mathrm{LiBr}$ was used as a solvent. Measurements were performed at $70{ }^{\circ} \mathrm{C}$ at a flow rate of $0.3 \mathrm{~mL} /$ min using a RI detector. Molecular weights of polymers were referenced to PS standards.

\section{Thermogravimetric Analysis}

Thermogravimetric analysis was performed in a PerkinElmer Pyris TGA1 instrument. The measurements were conducted by heating from 40 to $600{ }^{\circ} \mathrm{C}$ at a heating rate of $10{ }^{\circ} \mathrm{C} / \mathrm{min}$ under air atmosphere. The thermal behavior of the membranes was characterized by the onset decomposition temperature $\left(T_{\mathrm{OD}}\right)$ and the fastest decomposition temperature $\left(T_{\mathrm{FD}}\right)$. The values of $T_{\mathrm{OD}}$ and $T_{\mathrm{FD}}$ denote the temperature at which the weight loss begins and the temperature of the maximum in the weight loss rate, respectively. This last was determined by differential thermal analysis.

\section{Ion-Exchange Capacity}

The ion-exchange capacity (IEC) of the membranes herein studied was determined by titration using a 916 Ti-Touch titrator from Metrohm.
The membrane in the $\mathrm{OH}^{-}$form was immersed in a $0.1 \mathrm{M}$ standard hydrochloric acid solution for $48 \mathrm{~h}$. The resulting solution was titrated until $\mathrm{pH}=7$ with a $0.1 \mathrm{M} \mathrm{KOH}$ solution which was previously normalized with potassium hydrogenphtalate. In order to remove any remaining $\mathrm{HCl}$, the membrane was washed and immersed in deionized water for $24 \mathrm{~h}$. The resulting membrane was dried in an oven and then was weighed to determine the dry mass in the $\mathrm{Cl}^{-}$ form $\left(m_{\operatorname{dry}(\mathrm{Cl})}\right)$. The IEC was calculated as follow:

$$
I E C=\frac{n_{i\left(H^{+}\right)}-n_{f\left(H^{+}\right)}}{m_{d r y(\mathrm{Cl})}}
$$

Where $n_{\mathrm{i}\left(\mathrm{H}^{+}\right)}$and $n_{\mathrm{f}\left(\mathrm{H}^{+}\right)}$are the initial and the final moles of $\mathrm{H}^{+}$in the $\mathrm{HCl}$ solution, respectively.

\section{Water Uptake and Swelling Degree}

Water uptake (WU\%) and Swelling degree (SD\%) were determined by measuring the change in weight and thickness of the membranes before and after hydration, respectively. The dry membrane in $\mathrm{Cl}^{-}$form was immersed in a $1 \mathrm{M} \mathrm{KOH}$ solution for $48 \mathrm{~h}$ to replace $\mathrm{Cl}^{-}$with $\mathrm{OH}^{-}$, and, subsequently, washed with deionized water several times to remove the remaining $\mathrm{KOH}$.

The WU\% and SD\% values were then calculated according to the eqs 2 and 3, respectively, as follow:

$$
\begin{aligned}
\mathrm{WU} \% & =\frac{m_{\mathrm{hyd}(\mathrm{OH})}-m_{\mathrm{dry}(\mathrm{Cl})}}{m_{\mathrm{dry}(\mathrm{Cl})}} \times 100 \\
\mathrm{SD} \% & =\frac{x_{\mathrm{hyd}(\mathrm{OH})}-x_{\mathrm{dry}(\mathrm{Cl})}}{x_{\mathrm{dry}(\mathrm{Cl})}} \times 100
\end{aligned}
$$

Where $m_{\mathrm{dry}(\mathrm{Cl})}$ and $x_{\mathrm{dry}(\mathrm{Cl})}$ are the values of the mass and the thickness of the dry membrane in the $\mathrm{Cl}^{-}$form measured before hydration, and $m_{\text {hyd(OH) }}$ and $x_{\text {hyd(OH) }}$ are the values of the wet membrane in the $\mathrm{OH}^{-}$form.

\section{Mechanical Properties}

The mechanical properties of the membranes were evaluated from uniaxial tensile tests using a Universal Testing Machine (Shimadzu AG-I) with a load cell of $1 \mathrm{kN}$. The tests were carried out at room temperature with a crosshead speed of $0.5 \mathrm{~mm} \mathrm{m^{-1 }}$. The samples were cut into a size of $5 \mathrm{~mm}$ wide and $25 \mathrm{~mm}$ long and, the membrane thickness was in the $40-70 \mu \mathrm{m}$ range.

\section{Ionic Conductivity}

The ionic conductivity of the prepared membranes was determined by means of impedance spectroscopy (EIS). The measurements were performed using an impedance analyzer (Solartron 1260) together an electrochemical interface (Solartron 1287) in the frequency range between $10^{-1}$ and $10^{6} \mathrm{~Hz}$ by applying $\pm 10 \mathrm{mV}$ amplitude sinusoidal wave perturbation. The test cell used was constituted by two half-cells separated by two 0-rings where membrane was placed. ${ }^{33}$ A conventional electrochemical setup of four electrodes involving two saturated $\mathrm{Ag} / \mathrm{AgCl}$ electrodes as reference electrodes and two graphite electrodes as secondary electrodes was used. The 
electrochemical measurements were performed in different $\mathrm{KOH}$ solutions $\left(10^{-4} \leq c \leq 10^{-1} \mathrm{M}\right)$. Before testing, the membranes were in a $10^{-4} \mathrm{M} \mathrm{KOH}$ solution for $24 \mathrm{~h}$. Measurements at different temperatures were carried out in a Binder KMF 115(E5.2) constant climate chamber. Once the temperature was achieved, a waiting time of $15 \mathrm{~min}$ was defined before launching the measurement. The ionic conductivity of the membrane $\left(\sigma_{\mathrm{m}}\right)$ was calculated as follow:

$$
\sigma_{\mathrm{m}}=\frac{L}{R_{\mathrm{m}} \times A}
$$

Where $L, R_{\mathrm{m}}$, and $A$ are the thickness, resistance, and area of the membrane.

Z-View analysis impedance software (Scribner Associates, Inc., Southern Pines, NC) was used to analyze data obtained from the EIS measurements.

\section{Alkaline Stability}

The alkaline stability of PSU-BIm-OH membranes was evaluated by measuring the remaining BIm groups in the polymeric matrix after being treated in alkaline media for different times. PSU-BIm-Cl membranes were immersed in $1 \mathrm{M} \mathrm{KOH}$ solutions at room temperature for 6, 24, 48, 72, and $96 \mathrm{~h}$. Resulting membranes in the $\mathrm{OH}^{-}$form were washed with deionized water several times to remove residual $\mathrm{KOH}$ and dried in an oven before ${ }^{1} \mathrm{H}$-NMR analysis.

\section{RESULTS AND DISCUSSION}

\section{Synthesis of PSU-BIm-OH}

The chemical structure of the species involved in the synthesis of benzimidazolium-functionalized membranes (Fig. 1) was confirmed by ${ }^{1} \mathrm{H}-\mathrm{NMR}$ analysis. ${ }^{1} \mathrm{H}-\mathrm{NMR}$ spectra of PSU, CMPSU, m-BIm, and PSU-BIm-Cl are shown in Figure 2. The spectrum of PSU showed the peaks corresponding to phenyl and methyl groups at $\delta=6.9-7.9 \mathrm{ppm}$ and $\delta=1.7 \mathrm{ppm}$, respectively. ${ }^{32}$ The chloromethylation of PSU was confirmed by means of the appearance of the characteristic peak of $\mathrm{CH}_{2} \mathrm{Cl}$ group at $\delta=4.6 \mathrm{ppm}\left(H_{\mathrm{f}}\right){ }^{32}$ In addition, the signal associated with the proton located in $\alpha$ position with respect to the carbon containing the chloromethyl group was downshifted in CMPSU and it appeared at $7.5 \mathrm{ppm}\left(H_{\mathrm{g}}\right)$. Given that the $H_{\mathrm{a}}$ positions on PSU show the highest electron density, the electrophilic substitution is favored at these locations. $^{23}$ On the other hand, $H_{\mathrm{d}}$ positions show the lowest electron density and therefore, will not be affected by the chloromethylation reaction. So, the degree of chloromethylation (DC) could be successfully determined from the ${ }^{1} \mathrm{H}-\mathrm{NMR}$ spectrum (Fig. 2) according to the equation:

$$
\mathrm{DC}=\frac{2 A\left(H_{\mathrm{f}}\right)}{A\left(H_{\mathrm{d}}\right)}
$$

where $A\left(H_{\mathrm{f}}\right)$ and $A\left(H_{\mathrm{d}}\right)$ are the integral area of the $H_{\mathrm{f}}$ and $H_{\mathrm{d}}$ peak, respectively.

The presence of BIm groups in PSU-BIm-Cl was confirmed by the appearance of a new characteristic peak at $3.8 \mathrm{ppm}$
$\left(H_{\mathrm{h}}{ }^{\prime}\right)$ corresponding to the proton of methyl in m-BIm $\left(H_{\mathrm{h}}\right)$. The formation of benzimidazolium increased the acidity of $H_{\mathrm{i}}$ proton in m-BIm leading to the downshift of its signal $\left(H_{\mathrm{i}}^{\prime}\right)$. The complete conversion from a chloromethyl group to a benzimidazolium one was tested by the displacement of the proton signal of methylene from $4.6 \mathrm{ppm}\left(H_{\mathrm{f}}\right)$ in CMPSU to $5.8 \mathrm{ppm}\left(H_{\mathrm{f}}^{\prime}\right)$ in PSU-BIm-Cl.

FTIR analysis was also used to confirm the presence of BIm in the polymer. The FTIR spectra of CMPSU and PSU-BIm-Cl membranes are shown in Figure 3. A characteristic peak at $750 \mathrm{~cm}^{-1}$ in PSU-BIm spectrum, which was not observed in CMPSU, was associated with the bending vibrations of imidazolium groups, ${ }^{24,34}$ indicating the existence of these functional groups in the membrane.

To visualize the membrane morphology as a function of the percentage of BIm groups in the polymer, scanning electron microscopy was employed. The cross-section and surface of the membranes were inspected at $\times 5000$ magnification. At surface, PSU-BIm-OH 40\% membrane was tight in structure [Fig. 4(A)], while its homologue PSU-BIm-OH 140\% containing more BIm cations showed a porous structure [Fig. 4(B)]. However, the corresponding cross-section SEM micrographs of both membranes [Fig. 4(C,D)] revealed the absence of channels inside the polymer matrix which suggested that the formed pores in PSU-BIm-OH 140\% were not very deep, if only at superficial scale.

The molecular characteristics of the polymeric membranes evaluated by means of GPC analysis, revealed that the successive chemical reactions that occur in PSU (the chloromethylation of polysulfone followed by the nucleophilic substitution reaction of chloromethylated polysulfone with m-benzimidazole) did not modify considerably the polydispersity index (PI) of the polymer. The values of PI were 1.51 and 1.27 for PSU and PSU-BIm 80\%, respectively. These results suggest that there is no large dispersion of molecular weights, therefore improving the properties of the polymeric membrane.

\section{Thermal Stability}

In order to examine the thermal stability of PSU-BIm-OH membranes, a thermogravimetric analysis was performed. Figure 5 shows the TGA curves of PSU, CMPSU 80\%, and PSU-BIm-OH 80\% under air atmosphere. The behavior of these samples was characterized in the $40-600{ }^{\circ} \mathrm{C}$ range, by the $T_{\mathrm{OD}}$ and $T_{\mathrm{FD}}$ values.

As it is well known, PSU shows high thermal stability $\left(T_{\mathrm{OD}}=500{ }^{\circ} \mathrm{C}\right.$ and $T_{\mathrm{FD}}=530{ }^{\circ} \mathrm{C}$ ) and this behavior is attributed to its rigid aromatic structure. ${ }^{32}$ Typical degradation products include toluene, styrene, benzene, sulfur dioxide, and phenol. ${ }^{35}$ When the chloromethyl groups were added into the polymer backbone, the thermal stability of the resulting CMPSU decreased. So, two weight losses between 300 and $500{ }^{\circ} \mathrm{C}$ were observed which were assigned to the removal of methylene groups as well as the main chain decomposition $\left(T_{\mathrm{OD} 1}=350{ }^{\circ} \mathrm{C}\right.$ and $T_{\mathrm{FD} 1}=380{ }^{\circ} \mathrm{C} ; \quad T_{\mathrm{OD} 2}=460{ }^{\circ} \mathrm{C}$ and 

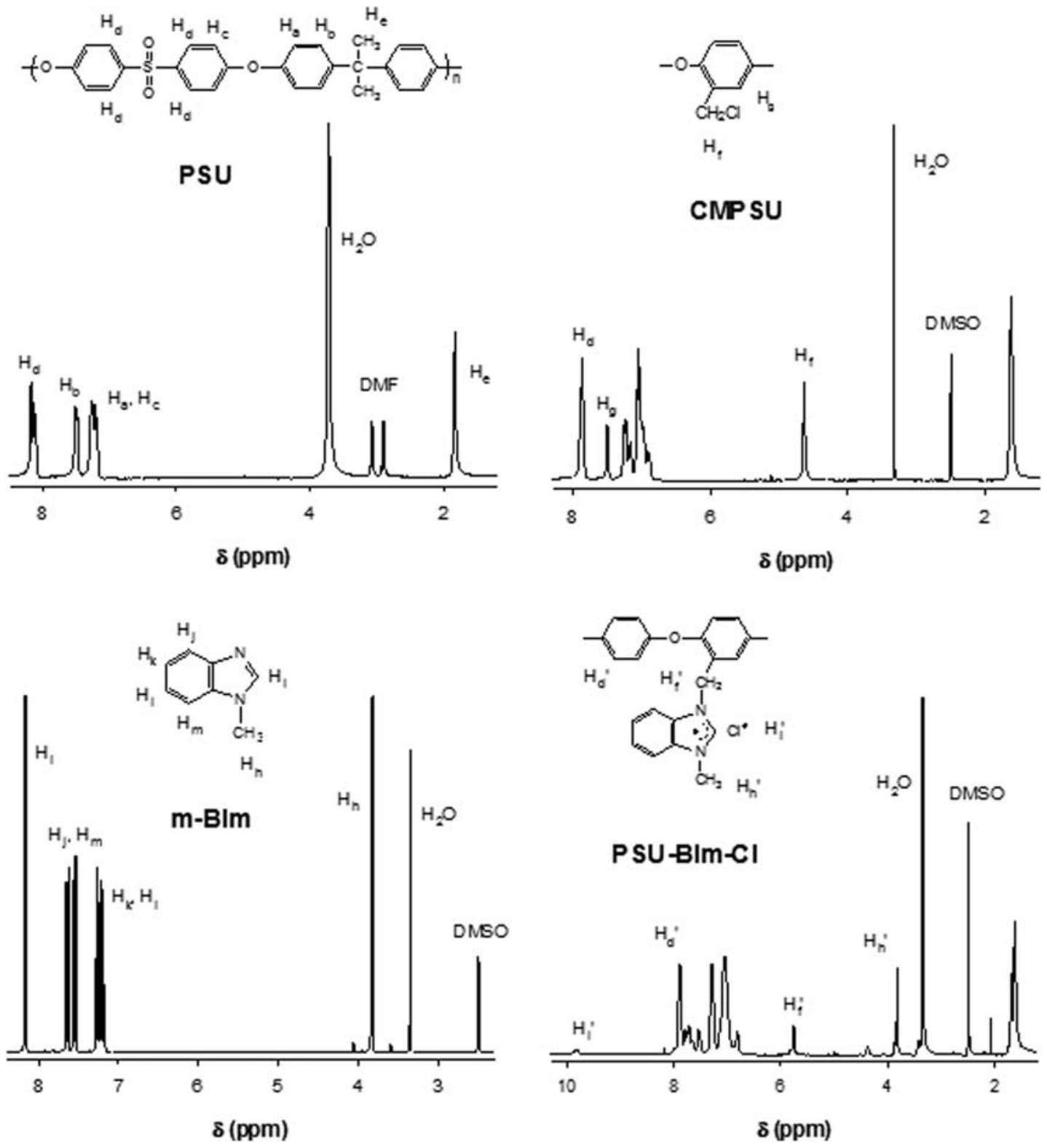

CMP SU

$\mathrm{H}_{2} \mathrm{O}$<smiles>CC1=CCC(OC2CCC(C)CC2CN2C=[N+](C)C3CCCCC32)CC1</smiles>

P SU-BIm-CI

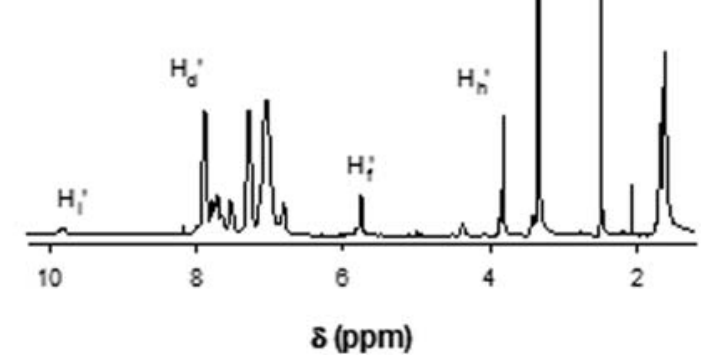

FIGURE $2{ }^{1} \mathrm{H}-\mathrm{NMR}$ spectra of PSU, CMPSU, m-BIm, and PSU-BIm-Cl.

$T_{\mathrm{FD} 2}=480^{\circ} \mathrm{C}$ ). A similar behavior was observed in all chloromethylated polysulfones here studied (data not shown).

On the other hand, the TGA curves of the PSU-BIm-OH membranes showed two main weight losses. The first loss $\left(T_{\mathrm{OD} 1}=220{ }^{\circ} \mathrm{C}\right.$ and $\left.T_{\mathrm{FD} 1}=290{ }^{\circ} \mathrm{C}\right)$ was attributed to the removal of the BIm groups ${ }^{27}$ and the second one $\left(T_{\mathrm{OD} 2}=410{ }^{\circ} \mathrm{C}\right.$ and $\left.T_{\mathrm{FD} 2}=470{ }^{\circ} \mathrm{C}\right)$ was assigned to the degradation of polymer backbone. The onset decomposition temperature of PSU-BIm-OH was slightly lower to the ones observed in other similar functional groups such as Im $\left(T_{\mathrm{OD}}=258{ }^{\circ} \mathrm{C}\right)^{23}$ and clearly higher than their equivalents containing quaternary ammonium $\left(T_{\mathrm{OD}}=120{ }^{\circ} \mathrm{C}\right){ }^{36}$ phosphonium $\left(T_{\mathrm{OD}}=186{ }^{\circ} \mathrm{C}\right)^{37}$ or guanidinium $\left(T_{\mathrm{OD}}=185{ }^{\circ} \mathrm{C}\right)^{18}$ groups. Subsequently, in view of the results, the polymeric material shows good thermal properties up to $220{ }^{\circ} \mathrm{C}$.

\section{Ion Exchange Capacity, Water Uptake and Swelling Degree}

The IEC reflects the amount of exchangeable groups in the membrane and consequently, it is directly related to the ionic conductivity. Therefore, the IEC value is expected to be as high as possible so as to provide a high ionic conductivity. Table 1 shows the variation of IEC (from 0.38 to $1.44 \mathrm{mmol}$ $\mathrm{g}^{-1}$ ) as a function of the DC value of the original polysulfone (from 40 to $140 \%$ ) for the membranes herein prepared. It is worth noting that the water uptake of PSU-BIm membranes increased (from 3.7 to $13.1 \%$ ) when IEC varied from 0.38 to $1.44 \mathrm{mmol} \mathrm{g}^{-1}$, and this variation was more pronounced for high IEC values. Thus, WU\% was tripled when IEC ranged from 0.41 to $1.44 \mathrm{mmol} \mathrm{g}^{-1}$. Imidazolium-functionalized polysulfones showed a similar trend showing a markedly increase on WU\% for high DC values. ${ }^{23}$ Attending to the 


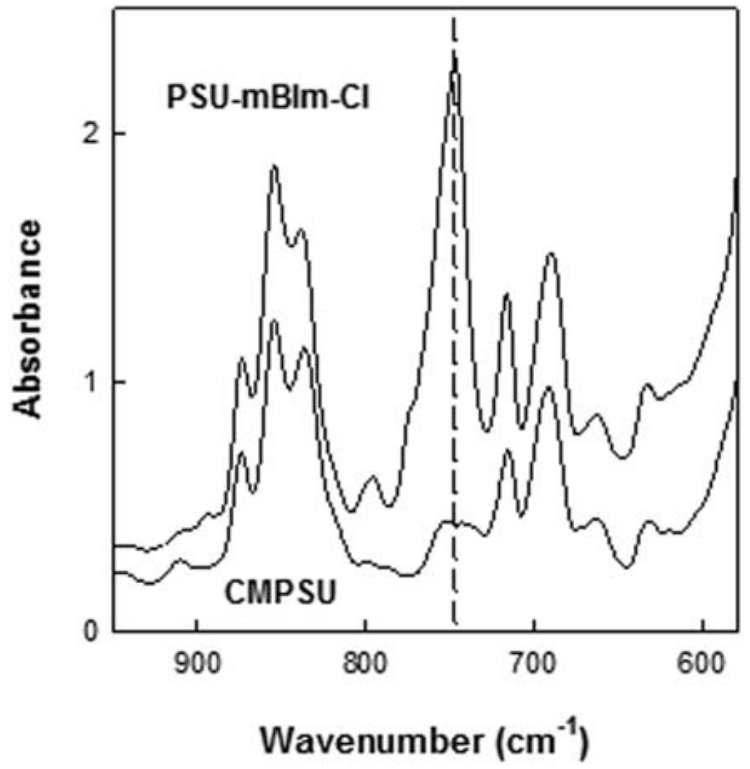

FIGURE 3 FTIR spectra of CMPSU and PSU-BIm-Cl membranes. Vertical dash line corresponds with the peak associated with the BIm group.

effect that the functional group has on the WU\% value, membranes containing quaternary ammonium groups (QAPSU-OH) exhibited a similar behaviour than PSU-BIm-OH
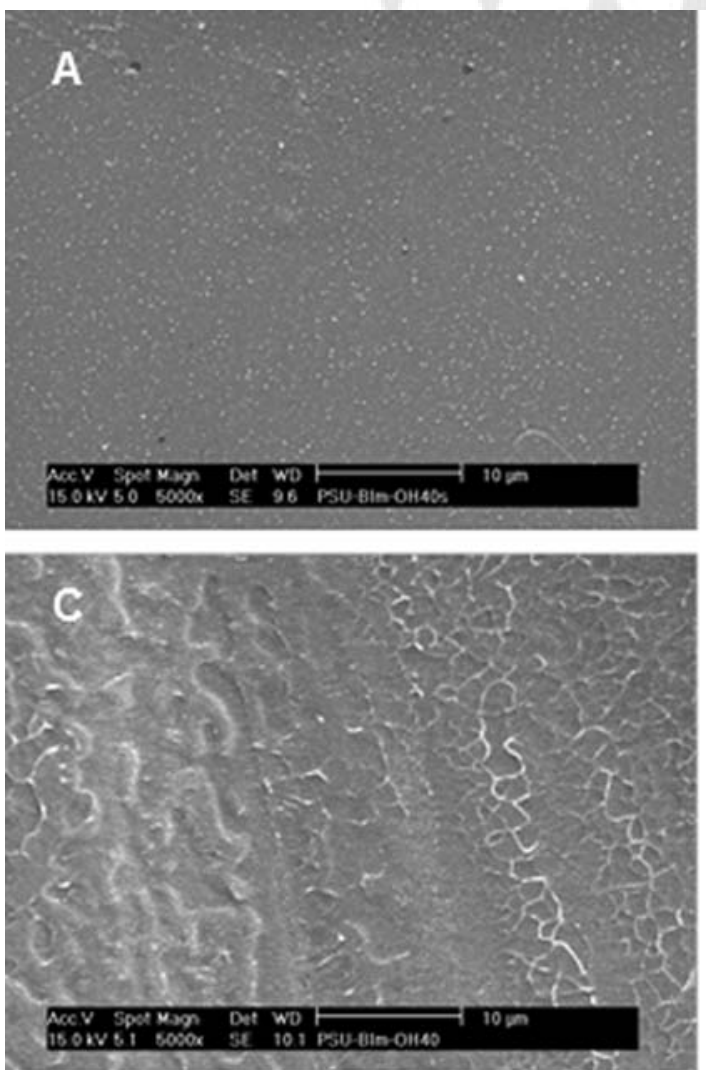

at a DC value of $100 \%$. As expected, the membrane dimensions were also enhanced by the addition of BIm groups, and, consequently, SD\% and WU\% followed a similar trend.

\section{Mechanical Properties}

The water content in the membrane as a consequence of the presence of cationic groups, evaluated by means of WU\% and SD\%, is closely related to the mechanical behavior of the polymeric material. Thus, the effect that the presence of BIm groups has on the mechanical properties of PSU-BIm membranes was studied by means of uniaxial tensile tests. Thus, membranes containing a high value of DC (100\%) were chosen. Thus, the tensile strength was $47 \mathrm{MPa}$ while the elongation at break was $9 \%$. When the benzimidazolium group was substituted by a quaternary ammonium, the tensile strength decreased until $27 \mathrm{MPa}$ while the elongation at break increased considerably up to $42 \%{ }^{38}$ It is noteworthy that membranes based on PPO containing these functional groups showed a similar behavior. ${ }^{27}$ As a result, the presence of a bulky substituent, like the aromatic ring, in benzimidazolium-functionalized membranes improved the mechanical strength of the polymer and reduced the ductility of the material.

\section{Ionic Conductivity}

Nyquist plots ( $-Z_{\text {img }}$ vs. $Z_{\text {real }}$ ) for PSU-BIm-OH membranes with different DC values (from 40 to $140 \%$ ), at a given $\mathrm{KOH}$ concentration, are shown in Figure 6. In all cases, two
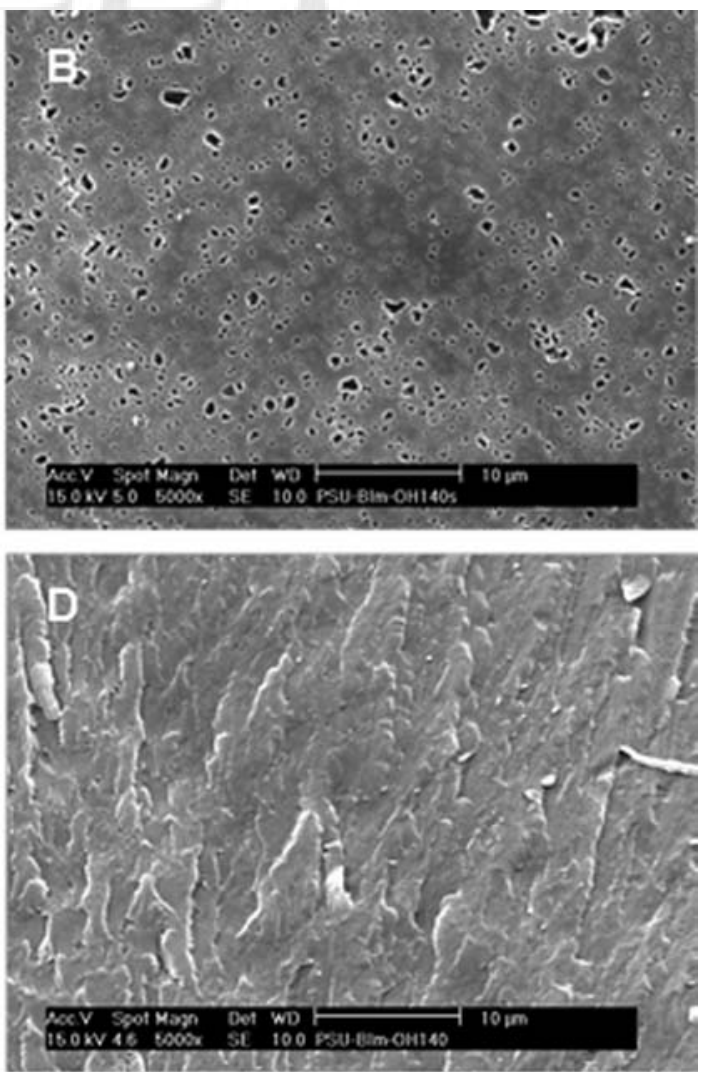

FIGURE 4 SEM micrographs of PSU-BIm-OH membranes at the surface for $\mathrm{DC}=40 \%(\mathrm{~A})$ and $140 \%$ (B) and the cross-section view for $\mathrm{DC}=40 \%(C)$ and $140 \%$ (D). 


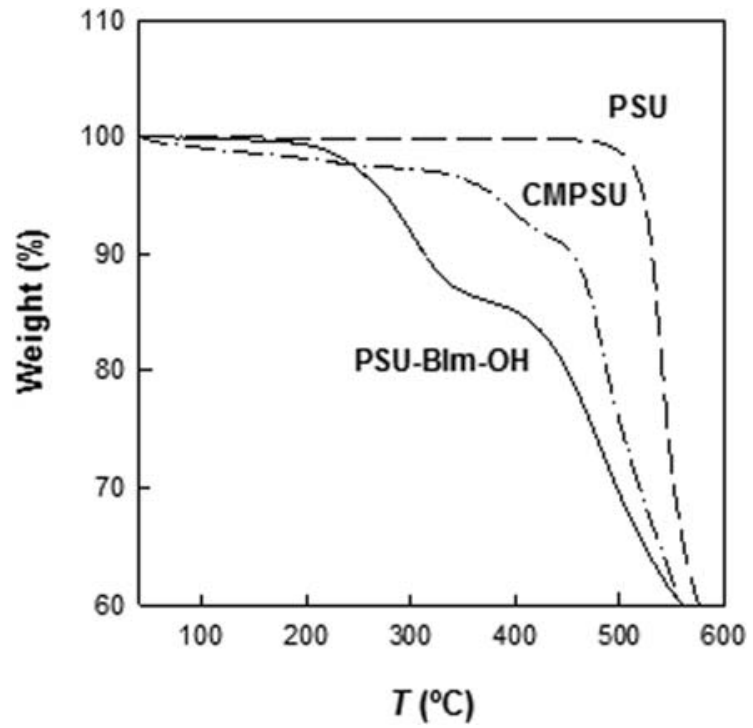

FIGURE 5 TGA curves for PSU, CMPSU 80\%, and PSU-BIm-OH $80 \%$ under air atmosphere.

semicircles were clearly distinguished which were associated with two different relaxation processes taking place in the electrolyte/membrane system. The high frequency arc (HFA) was not distorted and could be attributed to the electrolyte solution. This semicircle was reproduced considering a $\mathrm{R}_{\mathrm{e}} \mathrm{C}_{\mathrm{e}}$ parallel circuit. This behavior is consistent with the fact that the equivalent circuit for the electrolyte solution contains an ideal capacitor. ${ }^{39}$ The arc located at low frequency (LFA) was clearly distorted indicating a more complex system with different relaxation time. In this case, a nonideal capacitor or constant phase element $\left(Q_{\mathrm{m}}\right)$ in parallel with resistance $\left(R_{\mathrm{m}}\right)$ was required to reproduce the system. It is noteworthy that the size of this arc changed drastically with the chloromethylation degree of PSU and this fact could be associated with the membrane. Thus, for PSU-BIm-OH membranes with low DC values (40 and $80 \%$ ), the circuit corresponded to a $R_{\mathrm{m}} Q_{\mathrm{m}}$ parallel association, however, for high DC values (100 and 140\%) the best fitting of experimental data was observed by considering a circuit with a parallel association of a resistance $\left(R_{\mathrm{m}}\right)$ and a Warburg impedance $\left(W_{\mathrm{m}}\right)$. Therefore, the degree

TABLE 1 IEC, WU\%, and SD\% Values of AEMs

\begin{tabular}{llll}
\hline Membrane & \multicolumn{1}{c}{ IEC } \\
$\left(\mathrm{mmol} \mathrm{g}^{-1}\right)$ & WU\% ${ }^{\mathrm{a}}$ & SD\% ${ }^{\mathrm{a}}$ \\
PSU-BIm-OH 140\% & 1.44 & 13.1 & 24.7 \\
PSU-BIm-OH 100\% & 0.84 & 9.9 & 14.8 \\
PSU-BIm-OH 80\% & 0.41 & 4.7 & 4.6 \\
PSU-BIm-OH 40\% & 0.38 & 3.7 & 3.5 \\
QAPSU-OH $^{\mathrm{b}}$ & 0.70 & 5.7 & 10.0
\end{tabular}

\footnotetext{
a Room temperature
}

${ }^{b} \mathrm{DC}=100 \%{ }^{38}$ of chloromethylation influences greatly on the membrane's behavior, modifying the associated circuit type according to the transport process and likewise to the effect the sulfonation degree produces in PEMFCs. ${ }^{33}$ In all cases, the high frequency semicircle did not intercept the origin of the plot, indicating the presence of a resistive element $\left(R_{\mathrm{i}}\right)$ in series with the other two processes.

The proposed equivalent circuits associated with each membrane/electrolyte system are also shown in Figure 6.

The Bode plot ( $-Z_{\text {img }}$ versus frequency) allowed the determination of the frequency interval associated with each relaxation process. In the case of the HFA, the maximum frequency appeared around $2 \times 10^{5} \mathrm{~Hz}$, while the membrane contribution (LFA) was observed in the frequency range between 1 and $10^{4} \mathrm{~Hz}$ as can be seen in Figure 7. The value of the maximum frequency associated with the membrane varied as a function of the percentage of BIm groups in the membrane. In the case of sulfonated polysulfones of different sulfonation degree, the contribution of both membrane and electrolyte solution was in the range $10<$ frequency $(\mathrm{Hz})<6 \times 10^{4}$ and at a frequency higher than $6 \times 10^{4} \mathrm{~Hz}$, respectively. ${ }^{33}$ Therefore, it can be seen a certain similarity between the behavior of sulfonated and cloromethylated polysulfones in aqueous media.

The evolution of the membrane ionic resistivity $\left(r_{\mathrm{m}}\right)$ with $\mathrm{KOH}$ concentration is shown in Figure 8(A). For all PSU-BIm$\mathrm{OH}$ membranes, $r_{\mathrm{m}}$ decreased as $\mathrm{KOH}$ concentration increased in the $10^{-4}-10^{-1} \mathrm{M}$ range. This variation was more pronounced for high DC values. This fact reflects the great influence that the electrolyte solution embedded in the membrane network has on the electrochemical properties of this polymeric material. ${ }^{33,39-41}$

To evaluate how the ionic resistivity of PSU-BIm-OH membranes varied with respect to the percentage of BIm units, the CMPSU membrane was chosen as reference, as in this polymer the cationic groups responsible of the $\mathrm{OH}^{-}$transport do not exist and thus its ionic conductivity will be negligible. It is worth noting that the ionic conductivity of the polymeric membranes progressively increased more than two orders of magnitude when the DC value increased from 40 to $140 \%$ [Fig. 8(B)]. Consequently, the electrical properties of the membranes were strongly influenced by the degree of chloromethylation of polysulfone, which is an indicator of the percentage of BIm groups in the polymer chain. So, the highest $\sigma_{\mathrm{m}}$ values were achieved for the highest DC values. Furthermore, the fact that ionic conductivity did not increase for DC $>100 \%$, could be attributed to the steric effect of BIm groups located at the position two (Fig. 1). The effect that the presence of BIm units has on the ion conduction was also detected in functionalized membranes based on $\mathrm{PPO}^{27}$ The ionic conductivity of this polymer increased four times its value when the percentage of BIm groups varied from 9 to 54\%. In addition, a similar behavior was also observed when guanidinium groups were incorporated into the polymer. ${ }^{9}$ 

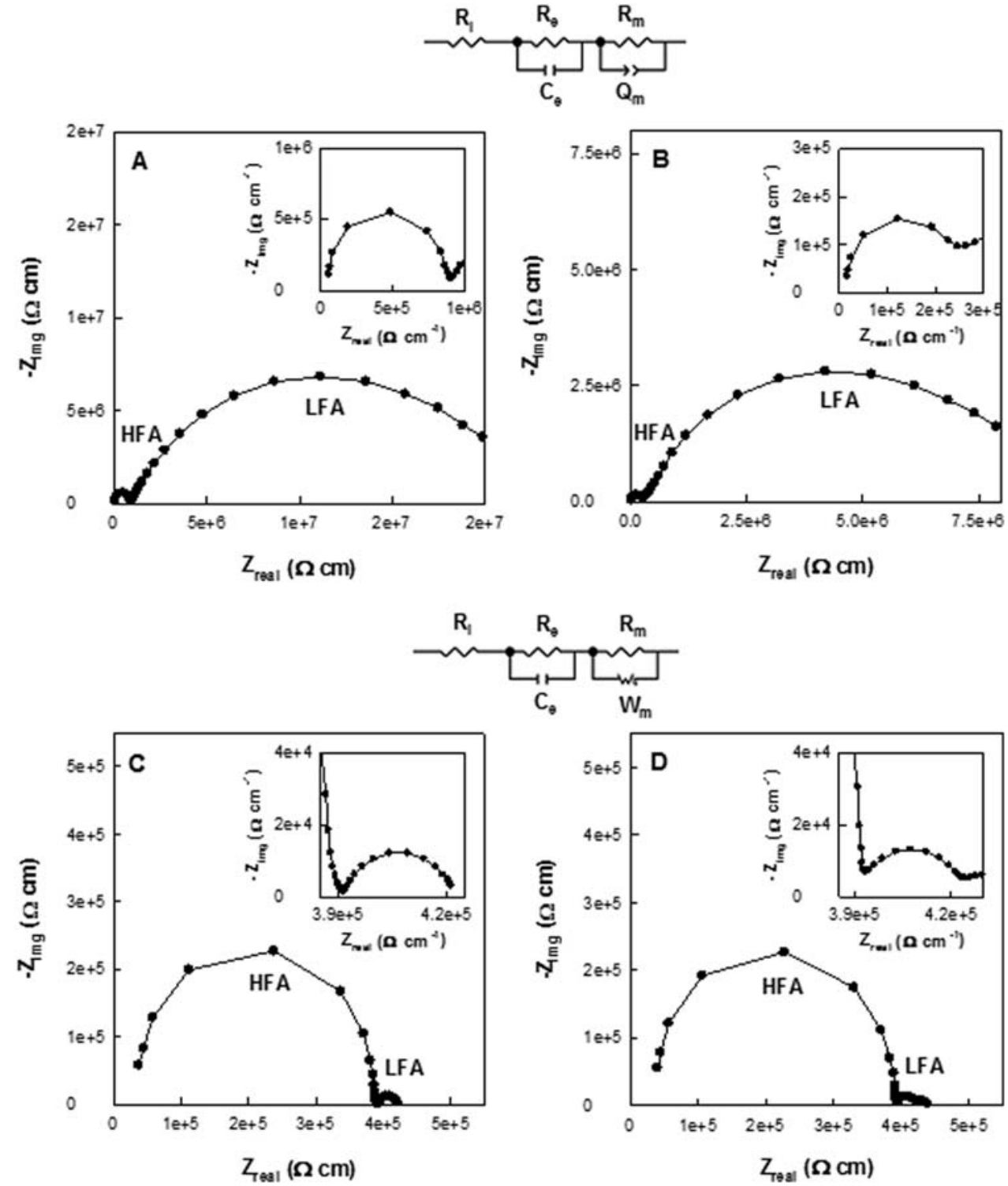

FIGURE 6 Impedance plots for the PSU-BIm-OH membranes with DC values of (A) $40 \%$, (B) $80 \%$, (C) $100 \%$, and (D) $140 \%$ at room temperature and $[\mathrm{KOH}]=10^{-3} \mathrm{M}$. Equivalent circuits associated with the electrolyte/membrane systems.

The influence that temperature has on the ionic conductivity was also evaluated. The experimental data obeyed Arrhenius law and the apparent activation energy $\left(E_{\mathrm{a}}\right)$ associated with the $\mathrm{OH}^{-}$transport through the membrane was easily obtained from the slope of the $\ln \sigma_{m}-1 / T$ plot. Table 2 shows the calculated $E_{\mathrm{a}}$ for PSU-BIm-OH membranes. There is no large variation of $E_{\mathrm{a}}$ values $(21-27 \mathrm{~kJ}$ $\mathrm{mol}^{-1}$ ). However the ionic conductivity was increased more than two orders of magnitude (from $2.0 \times 10^{-7}$ to $2.4 \times$ $10^{-5} \mathrm{~S} \mathrm{~cm}^{-1}$ at a $\mathrm{KOH}$ concentration of $10^{-2} \mathrm{M}$ ) when the DC value varied from 40 to $140 \%$. This behavior could be explained in ionic mobility terms. In general, the ionic conductivity depends on the number of charge carriers and their mobility in the electrolyte, and can be easily defined as follows:

$$
\sigma=\sum n_{i} z_{i} \mu_{i}
$$

Where $n_{i}, z_{i}$, and $\mu_{i}$ are the number of charge carriers, the ionic charge, and the ionic mobility, respectively. Therefore, the enhancement of ionic conductivity can be performed by increasing $n_{i}$ which can be obtained experimentally by incorporating of BIm cations in the polymeric matrix.

A major difference in the value of the activation energy was observed by modifying the cationic functional group of the membrane. Thus, QAPSU-OH ${ }^{38}$ showed a higher value of $E_{\mathrm{a}}$ than those observed for PSU-BIm-OH membranes and the ionic conductivity, at room temperature, was slightly lower (Table 2). When compared to Nafion $117\left(12 \mathrm{~kJ} \mathrm{~mol}^{-1}\right),{ }^{42}$ AEMs showed higher $E_{\mathrm{a}}$ values. This fact can be attributed to 


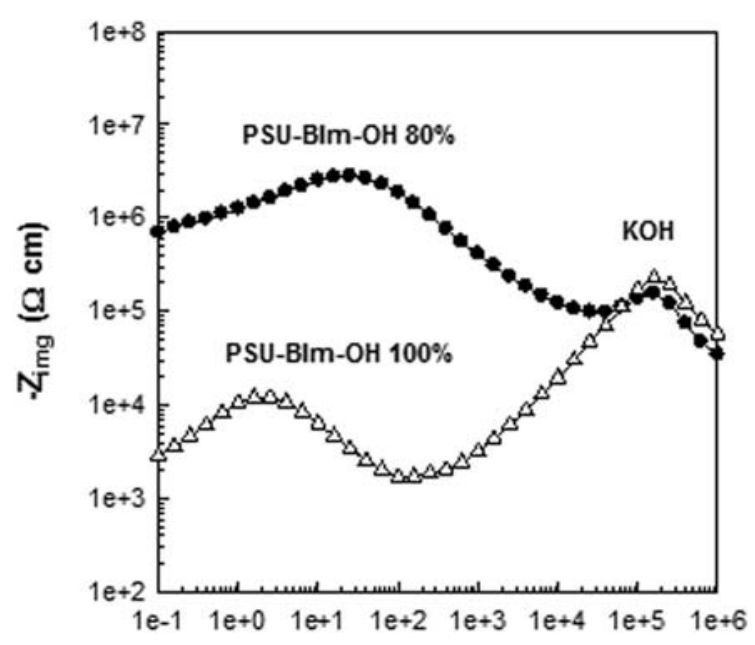

Frequency $(\mathrm{Hz})$

FIGURE 7 Bode plot for PSU-BIm-OH membranes with a DC value of $80 \%(\bullet)$ and $100 \%(\Delta)$ at room temperature and $[\mathrm{KOH}]=10^{-3} \mathrm{M}$.

that the diffusion coefficient of $\mathrm{H}^{+}$is usually four times higher than for $\mathrm{OH}^{-}$and, consequently, in order to get the same results, it would be necessary to have a concentration of $\mathrm{OH}^{-}$ions in the alkaline membrane four times higher than in the acidic one. ${ }^{43}$ However, the ionic conductivity of the perfluorinated membrane $\left(17 \times 10^{-6} \mathrm{~S} \mathrm{~cm}^{-1}\right)$ was the same order of magnitude than those obtained for PSU-BIm$\mathrm{OH}$ membranes measured under equivalent experimental conditions.

\section{Alkaline Stability}

The alkaline stability of the AEMs must be sufficiently high so that they can be successfully used in fuel cells. Quaternary ammonium ${ }^{44}$ or guanidium ${ }^{45}$ are two of the most common functional groups with low stability in alkaline media. In the case of BIm groups, their corresponding hydroxides
TABLE 2 Activation Energy and lonic Conductivity Values of AEMs

\begin{tabular}{lll}
\hline Membrane & $\begin{array}{c}E_{\mathrm{a}} \\
\left.(\mathrm{kJ} \mathrm{mol})^{-1}\right)^{\mathrm{a}}\end{array}$ & $\begin{array}{l}10^{6} \times \sigma_{\mathrm{m}} \\
\left(\mathrm{S} \mathrm{cm}^{-1}\right)^{\mathrm{b}}\end{array}$ \\
PSU-BIm-OH 140\% & $21 \pm 2$ & 23.8 \\
PSU-BIm-OH 100\% & $24 \pm 1$ & 21.2 \\
PSU-BIm-OH 80\% & $27 \pm 3$ & 1.0 \\
PSU-BIm-OH 40\% & - & 0.2 \\
QAPSU-OH $^{\mathrm{c}}$ & $63 \pm 1$ & 8.5
\end{tabular}

${ }^{\mathrm{a}}[\mathrm{KOH}]=10^{-3} \mathrm{M}$

${ }^{\mathrm{b}}$ Room temperature and $[\mathrm{KOH}]=10^{-2} \mathrm{M}$

${ }^{c} \mathrm{DC}=100 \%^{38}$

are known to be unstables. Thus, the $\mathrm{C} 2$ position in this molecule is usually susceptible to nucleophilic attack by $\mathrm{OH}^{-}$ making this material able to degrade in alkaline solutions. ${ }^{46}$

In this scenario, the stability of PSU-BIm-OH membranes in alkaline media was evaluated by measuring the BIm groups remaining after being treated with a $1 \mathrm{M} \mathrm{KOH}$ solution for different times comprising from 6 to $72 \mathrm{~h}$. The content of remaining BIm groups was quantitatively calculated through ${ }^{1} \mathrm{H}-\mathrm{NMR}$ analysis by comparing the integral area of $H_{\mathrm{f}}$ and $H_{\mathrm{d}}$ peaks in PSU-BIm membrane (Fig. 2) and likewise to the determination of DC carried out in CMPSU (see eq 5). Considering the overall balanced properties of benzimidazoliumfunctionalized membranes studied here, PSU-BIm-OH 100\% was chosen for testing the alkaline stability of these materials. Figure 9 shows the alkaline degradation rates for PSUBIm-OH $100 \%$ membranes. The $100 \%$ value for the remaining BIm groups percentage, corresponds to those determined for the membrane in the $\mathrm{Cl}^{-}$form. With increasing the treatment time decreased the percentage of BIm groups in the polymeric membrane. A clear decrease in the number of BIm groups of around $10 \%$ was observed when the membrane was treated for $6 \mathrm{~h}$. For long-time treatments of about $96 \mathrm{~h}$ the loss of functional groups achieved a value of $40 \%$. In
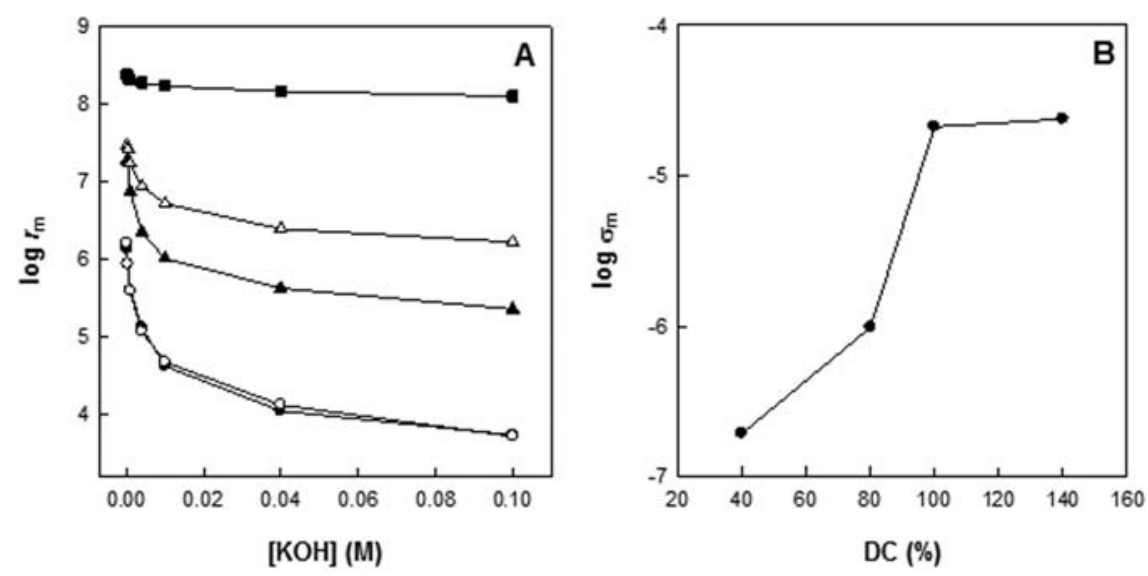

FIGURE 8 (A) Variation of the membrane ionic resistivity at room temperature, with the concentration of KOH for CMPSU membrane without BIm cations ( $\square$ ), and PSU-BIm-OH membranes: $40(\Delta), 80(\mathbf{\Delta}), 100(\bigcirc)$, and 140\% (•). (B) Evolution of membrane ionic conductivity at room temperature with the $\mathrm{DC}$ value at a given $\mathrm{KOH}$ concentration of $10^{-2} \mathrm{M}$. 


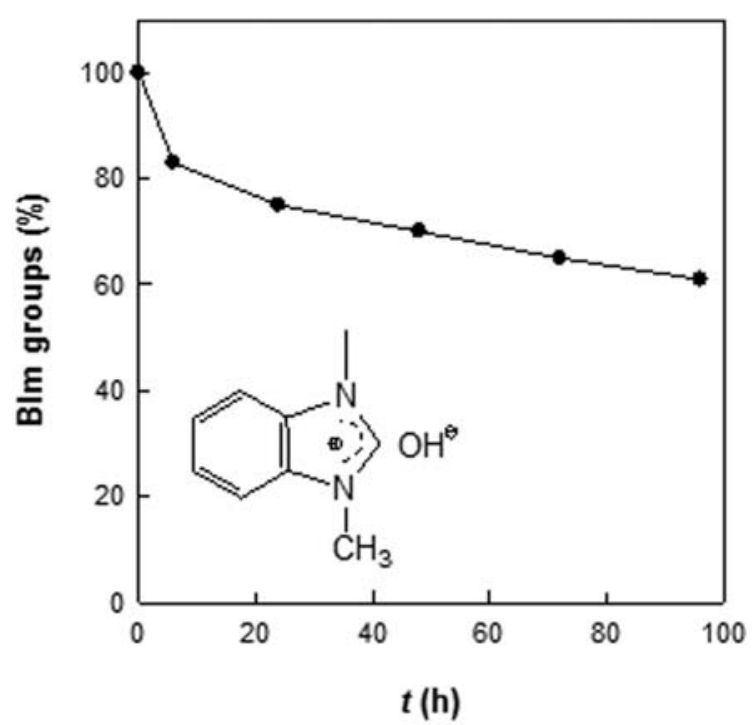

FIGURE 9 Alkaline stability of PSU-BIm-OH 100\% membranes in $1 \mathrm{M} \mathrm{KOH}$ solution at different times.

this work, PSU-BIm-OH membranes were prepared by treating the membrane in the $\mathrm{Cl}^{-}$form with a $1 \mathrm{M} \mathrm{KOH} \mathrm{solution}$ for $48 \mathrm{~h}$ (see Experimental Section). Under these experimental conditions a loss of BIm groups in the membranes of around 30\% was observed. Although these are not the best conditions, PSU-BIm-OH membranes showed good electrochemical properties (Fig. 8). Therefore, an improvement on the membrane characteristics as electrolyte can be achieved by reducing the time of the alkaline treatment.

A similar behavior has been reported in PPO based membranes containing pendant BIm groups. ${ }^{27}$ In this study, the results revealed that IEC, WU\%, and ionic conductivity of the BIm-PPO membranes decreased by 18,27 , and $35 \%$, respectively, after alkaline treatment. At this point, the chemical modification of benzimidazolium groups may be a good alternative to minimize its degradation. A recently published work revealed the possibility of improving hydroxide stability in neutral and $\mathrm{KOH}$ solutions by steric crowding around the reactive $\mathrm{C} 2$ position of the benzimidazolium group by the incorporation of adjacent bulky groups which hinder nucleophilic attack by $\mathrm{OH}^{-}{ }^{46}$ Therefore, the properties of the material can be noticeably improved by modifying not only the chemical structure of the polymer, but also the alkaline treatment.

\section{CONCLUSIONS}

In this work, a series of novel benzimidazoliumfunctionalized polysulfones were successfully synthesized and characterized. Polysulfone was firstly chloromethylated followed by nucleophilic substitution reaction with 1methylbenzimidazole. The structures of the polymers were characterized by ${ }^{1} \mathrm{H}-\mathrm{NMR}$ and FTIR analysis. The resulting AEMs showed higher thermal stability than their homologue containing quaternary ammonium groups. The higher values for water uptake and swelling degree were achieved in the
IEC range between 0.8 and $1.5 \mathrm{mmol} \mathrm{g}^{-1}$. The presence of benzimidazolium groups instead of quaternary ammonium ones improved the mechanical strength of the polymer (from 27 to $47 \mathrm{MPa}$ ). The ionic conductivity of the membranes in dilute aqueous solution of potassium hydroxide was studied by means of impedance spectroscopy. The results show not only a clear correlation between the membrane's electrochemical behaviour with the electrolyte solution embedded in the membrane, but also with the degree of the polysulfone's chloromethylation. Thus, the ionic conductivity increased more than two orders of magnitude when the degree of chloromethylation increased from 40 to $140 \%$. The values of the apparent activation energy associated with the ionic transport were in the $21-27 \mathrm{~kJ} \mathrm{~mol}^{-1}$ range depending on the degree of chloromethylation. Therefore, the membranes here studied could be considered promising materials for being satisfactorily used as electrolytes in AEMFCs.

\section{ACKNOWLEDGMENT}

This work has been supported by the Projects from the regional government (Comunidad de Madrid through MATERYENER3CM S2013/MIT-2753) and Spanish Government, MINECO (MAT2013-46452-C4-3R).

\section{REFERENCES}

1 J. R. Varcoe, P. Atanassov, D. R. Dekel, A. M. Herring, M. A. Hickner, P. A. Kohl, A. R. Kucernak, W. E. Mustain, K. Nijmeijer, K. Scott, T. Xu, L. Zhuang, Energy Environ. Sci. 2014, 7, 31353191.

2 G. F. McLean, T. Niet, S. Prince-Richard, N. Djilali, Int. J. Hydrogen Energy 2002, 27, 507-526.

3 J. R. Varcoe, R. C. T. Slade, Fuel Cells 2005, 5, 187-200.

4 A. Holewinski, J. C. Idrobo, S. Linic, Nat. Chem. 2014, 6, 828834.

5 S. Lu, J. Pan, A. Huang, L. Zhuang, J. Lu, Proc. Natl. Acad. Sci. USA 2008, 105, 20611-20614.

6 P. Manivasakan, P. Ramasamy, J. Kim, Nanoscale 2014, 6, 9665-9672.

7 G. Couture, A. Alaaeddine, F. Boschet, B. Ameduri, Progr. Polymer Sci. 2011, 36, 1521-1557.

8 S. Maurya, S. H. Shin, M. K. Kim, S. H. Yun, S. H. Moon, J. Membrane Sci. 2013, 443, 28-35.

9 X. Lin, L. Wu, Y. Liu, A. L. Ong, S. D. Poynton, J. R. Varcoe, T. Xu, J. Power Sources 2012, 217, 373-380.

10 H. Zarrin, G. Jiang, G. Y. Y. Lam, M. Fowler, Z. Chen, Int. J. Hydrogen Energy 2014, 39, 18405-18415.

11 A. H. N. Rao, R. L. Thankamony, H. J. Kim, S. Nam, T. H. Kim, Polymer 2013, 54, 111-119.

12 Z. Liu, X. Zhu, G. Wang, X. Hou, D. Liu, J. Polym. Sci. Pol. Phys. 2013, 51, 1632-1638.

13 L. Zeng, T. S. Zhao, Y. S. Li, Int. J. Hydrogen Energy 2012, 37, 18425-18432.

14 M. L. Di Vona, R. Narducci, L. Pasquini, K. Pelzer, P. Knauth, Int. J. Hydrogen Energy 2014, 39, 14039-14049.

15 J. Zhou, J. Guo, D. Chu, R. Chen, J. Power Sources 2012, 219, 272-279. 
16 J. Miyake, K. Fukasawa, M. Watanabe, K. Miyatake, J. Polym. Sci. Part A: Polym. Chem. 2014, 52, 383-389.

17 C. G. Arges, J. Parrondo, G. Johnson, A. Nadhan, V. Ramani, J. Mater. Chem. 2012, 22, 3733-3744.

18 J. Wang, S. Li, S. Zhang, Macromolecules 2010, 43, 3890-3896. 19 A. Vöge, V. Deimede, J. K. Kallitsis, RSC Adv. 2014, 4, 45040-45049.

20 Y. Ye, Y. A. Elabd, In Polymers for energy storage and delivery: Polyelectrolytes for Batteries and Fuel Cells; K.A. Page, C.L.Soles, J.Runt, Eds.; ACS Symposium Series 1096; American Chemical Society: Washington, DC, 2012; p 233.

21 B. Lin, L. Qiu, B. Qiu, Y. Peng, F. Yan, Macromolecules 2011, $44,9642-9649$.

22 B. Qiu, B. Lin, Z. Si, L. Qiu, F. Chu, J. Zhao, J. Power Sources 2012, 217, 329-335.

23 X. Yan, G. He, S. Gu, X. Wu, L. Du, Y. Wang, Int. J. Hydrogen Energy 2012, 37, 5216-5224.

24 J. Ran, L. Wu, J. R. Varcoe, A. L. Ong, S. D. Poynton, T. Xu, J. Membrane Sci. 2012, 415, 242-249.

25 J. A. Asensio, S. Borrós, P. Gómez-Romero, J. Polym. Sci. Part A: Polym. Chem. 2002, 40, 3703-3710.

26 Z. Xia, S. Yuan, G. Jiang, X. Guo, J. Fang, L. Liu, J. Qiao, J. Yin, J. Membrane Sci. 2012, 390, 152-159.

27 X. Lin, X. Liang, S. D. Poynton, J. R. Varcoe, A. L. Ong, J. Ran, Y. Li, Q. Li, T. Xu, J. Membrane Sci. 2013, 443, 193-200.

28 P. T. Nonjola, M. K. Mathe, R. M. Modibedi, Int. J. Hydrogen Energy 2013, 38, 5115-5121.

29 J. E. Harris, In Engineering Thermoplastics: Properties and Applications; Margolis J. M., Eds.; Dekker: New York, 1985; pp 177-200.

$30 \mathrm{~J}$. D. Muzzy, In Comprehensive Composite Materials; A.Kelly, C.Zweben, Eds.; Elsevier Science: Amsterdam, 2000; Vol. 2, pp 57-76.
31 N. Pantamas, C. Khonkeng, S. Krachodnok, A. Chaisena, Am. J. Applied Sci. 2012, 9, 1577-1582.

32 E. Avram, M. A. Brebu, A. Warshawsky, C. Vasile, Polym. Degrad. Stabil. 2000, 69, 175-181.

33 J. Benavente, J. M. García, R. Riley, A. E. Lozano, J. de Abajo, J. Membr. Sci. 2000, 175, 43-52.

34 K. Malek, A. Puc, G. Schroeder, V. I. Rybachenko, L. M. Proniewicz, Chem. Phys. 2006, 327, 439-451.

35 G. Molnár, A. Botvay, L. Pöppl, K. Torkos, J. Borossay, A. Máthe, T. Török, Polym. Degrad. Stabil. 2005, 89, 410-417.

36 J. Pan, S. Lu, Y. Li, A. Huang, L. Zhuang, J. Lu, Adv. Funct. Mater. 2010, 20, 312-319.

37 S. Gu, R. Cai, Y. Yan, Chem. Commun. 2011, 47, 2856-2858.

38 M. T. Pérez-Prior, T. García-García, A. Várez, B. Levenfeld, J. Mater. Sci., in press.

39 J. Benavente, X. Zhang, R. Garcia Valls, J. Colloid. Int. Sci. 2005, 285, 273-280.

40 P. Aranda, J. C. Galván, B. Casal, E. Ruiz-Hitzky, Colloid Polym. Sci. 1994, 272, 712-720.

41 L. An, T. S. Zhao, O. X. Wu, L. Zeng, Int. J. Hydrogen Energy 2012, 37, 14536-14542.

42 J. S. Park, J. W. Park, E. Ruckenstein, J. Appl. Polym. Sci. 2001, 80, 1825-1834.

43 E. Agel, J. Bouet, J. F. Fauvarque, J. Power Sources 2001, 101, 267-274.

44 J. A. Vega, C. Chartier, W. E. Mustain, J. Power Sources, 2010, 195, 7176-7180.

45 L. Liu, Q. Li, J. Dai, H. Wang, B. Jin, R. Bai, J. Membrane Sci. 2014, 453, 52-60.

46 O. D. Thomas, K. J. W. Y. Soo, T. J. Peckham, M. P. Kulkarni, S. Holdcroft, J. Am. Chem. Soc. 2012, 134, 1075310756.

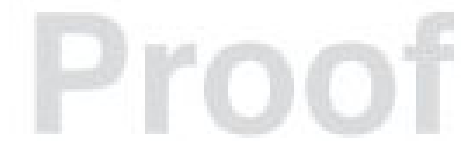

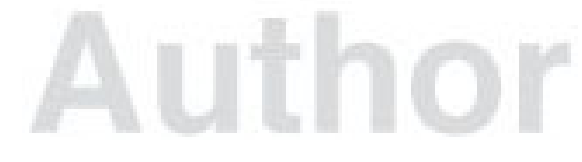




\section{SGML and CITI Use Only DO NOT PRINT}

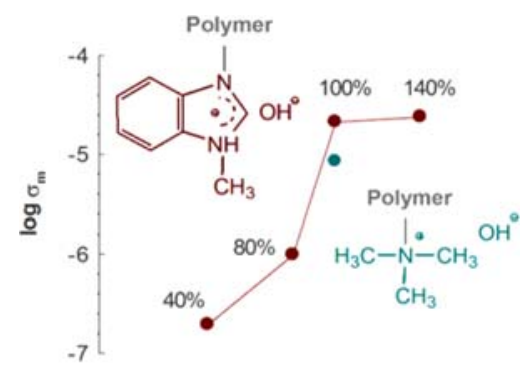

Degree of chloromethylation

\begin{abstract}
A series of benzimidazolium-functionalized polysulfones were synthesized and characterized. The electrochemical behavior of the resulting anion-exchange membranes showed a clear dependence with the degree of chloromethylation of polysulfone. Thus, the ionic conductivity increased more than two orders of magnitude when the degree of chloromethylation increased from 40 to $140 \%$. In addition, the presence of benzimidazolium groups instead of the widely used quaternary ammonium ones improved the ionic conductivity of the polymeric membranes.
\end{abstract}

